\author{
ARTÍCULO INVITADO \\ Social liberalismo y dominación global* \\ José Maurício DOMINGUES \\ Instituto de Estudos Sociais e Políticos (IESP) \\ Universidade Estadual de Rio de Janeiro \\ jmdomingues@iesp.uerj.br
}

Recibido: 06-03-2014

Aceptado: 29-04-2014

\begin{abstract}
RESUMEN
El neoliberalismo fue sumamente importante en la transición para la actual fase de la modernidad. Pero desde los años 1990 un tipo de social liberalismo también es crucial en la organización de las formas presentes de dominación global, incluidas ahí las formas de gubernamentalidad que moldean las subjetividades contemporáneas. Este artículo investiga las formas de serialidades cerradas y políticas sectorizadas y focales que subyacen al social liberalismo. Se contraponen a ellas, aunque no de manera absoluta, una perspectiva de serialidades abiertas y políticas sociales universalistas, hacia una forma de solidaridad compleja.
\end{abstract}

Palabras clave: social liberalismo; política social; Banco Mundial; pobreza; Brasil.

\title{
Social liberalism and global domination
}

\begin{abstract}
Neoliberalism was paramount in the transition to the present phase of modernity. But since the 1990s a sort of social liberalism has been also crucial to the organization of current forms of global domination, including the forms of governmentality that shape contemporary subjectivities. This article investigates the closed forms of seriality as well as sectoralized and target policies that underlie social liberalism. It is counter-posed to them, though not in an absolute manner, a perspective of open serialities and universalist social policies, towards a complex solidarity.
\end{abstract}

Key words: social liberalism; social policy; World Bank; poverty; Brazil.

\footnotetext{
* Traducción de Maximiliano Duarte. Una versión en portugués apareció en Mulemba. Revista Angolana de Sociologia, vol. 3, núm. 6, 2013.
} 


\title{
Social liberalismo e dominação global
}

\begin{abstract}
RESUMO
O neoliberalismo foi altamente importante na transição para a atual fase da modernidade. Mas desde os anos 1990 um tipo de social liberalismo é também crucial na organização das formas presentes de dominação global, incluídas aí as formas de governamentalidade que moldam as subjetividades contemporâneas. Este artigo investiga as formas de serialidades fechadas e políticas setorializadas e focais que subjazem ao social liberalismo. Contrapõe-se a elas, embora não de maneira absoluta, uma perspectiva de serialidades abertas e políticas sociais universalistas, na direção de uma forma de solidariedade complexa.
\end{abstract}

Palavras-chave: social liberalismo; política social; Banco Mundial; pobreza; Brasil.

REFERENCIA NORMALIZADA

Domingues, José Maurício (2013) "Social liberalismo y dominación global”. Geopolítica(s). Revista de estudios sobre espacio y poder, vol. 4, núm. 2, 183-198.

SUMARIO: Introducción: neoliberalismo y social liberalismo. 1. De los derechos a las políticas particularizantes. 2. Individualismo, particularismo y universalismo, pluralismo y complejidad. 3. ¿Políticas públicas más allá del social liberalismo? Conclusión. Bibliografía.

\section{Introducción: neoliberalismo y social liberalismo}

El neoliberalismo apareció hace muchos años como un proyecto al que nadie originariamente dio mucha atención. Nació de los esfuerzos de varios economistas concentrados en esta tarea intelectual. Entre ellos destacaba Hayek, como se sabe, pero muchos otros académicos importantes también tomaron parte en su articulación intelectual y práctica. Pasaron varios años hasta que los neoliberales llegaron al poder del Estado, una vez que el keynesianismo y el Estado del bienestar, el desarrollismo y formas corporativistas de organizar la política social acotaban el espacio en que sus doctrinas podían expandirse y desarrollar su ímpetu político concreto. Finalmente alcanzó hegemonía mundial, iniciándose el periodo de su ascenso con las dictaduras de Pinochet y Videla, respectivamente en Chile y Argentina, después con Reagan y Thatcher, en Estados Unidos e Inglaterra. Con la crisis creciente -real o imaginada, financiera y/o política- del keynesianismo, del desarrollismo del Tercer Mundo y de las políticas sociales englobantes del Estado del bienestar, logró alcanzar hegemonía y diseñar el mundo de manera intensa y de acuerdo a su visión. Ésta incluía políticas económicas, de las que el llamado Consenso de Washington terminó siendo la expresión por antonomasia. Además, desde entonces generaciones sucesivas de "reformas" intentaron crear condiciones institucionales para su implementación, que iban desde las privatizaciones hasta la reformulación de la justicia. Pero conllevaban también, como lo demostró Foucault ([1978-79] 2004), una concepción ("biopolítica") de las personas, a las cuales se debería enten- 
der como "empresas", racional y sistemáticamente proyectadas, subjetivamente encerradas en una carrera y trayectoria de vida, con planes de inversión y cálculos de costo-beneficio. El neoliberalismo se movió así entre concepción del mundo, proyecto político y políticas públicas (véase Anderson, 1995; Harvey, 2007).

El neoliberalismo ya fue analizado muchas veces, en sus diversas vertientes. No es la intención de este texto retomar o profundizar este sendero de investigación, sino indagar que pasó después de su consolidación como política económica, aunque partes significativas del mundo hayan seguido sólo parcialmente sus recetas (este es el caso de China, otros países reculando de su acatamiento luego de procesos absolutamente desastrosos, como en el caso de Rusia). En verdad, el propósito de este texto es investigar lo que se puede tachar en cierta medida de sucesor del neoliberalismo, es decir, el social liberalismo. Éste no se opone necesariamente y, de hecho, no enteramente al neoliberalismo, compartiendo con él muchos elementos y perspectivas, pero ya no se contenta simplemente con afirmar el mercado y el racionalismo de la empresa en todas las dimensiones, mezclando economía y "biopolítica" de manera todavía más amplia y sutil. Ésta última en particular se expandió con el social liberalismo, que astutamente supo responder a demandas fundamentales de la sociedad y con ello consolidó la hegemonía del liberalismo en el mundo. Si el neoliberalismo, evidenciando fuertes elementos de continuidad con el liberalismo - pero, como argumentaré, desechando lo que fue en principio su postulación de derechos-, fue decisivo para la ampliación de lo que muchos todavía denominan "Imperio americano" (Panitch y Gindin, 2012), el social liberalismo es crucial para su administración sobre todo en regiones del mundo en que las demandas populares se afirman y el problema de la pobreza es sobresaliente.

Como veremos, el Banco Mundial es la institución clave en este proceso. Inventó o supo - sigue sabiendo- aprovechar innovaciones que aparecen en lo que se llama convencionalmente "Sur global". Esto es especialmente verdadero en lo que tiene que ver con los "programas de transferencias monetarias condicionadas", en particular en Sudamérica, África y el sur de Asia —incluyendo no solamente Brasil, Colombia, México, Chile, Nicaragua y casi todos los otros países latinoamericanos, sino también Turquía, Burkina Faso, Bangladesh, Indonesia, Camboya, Sudáfrica, Marruecos, Malawi, India, Nigeria, Filipinas y Yemen-. Políticas focalizadas y sectoriales son decisivas para su articulación, que fragmenta y reconstituye el tejido social buscando su funcionamiento vertical, sin contraponerse, por otra parte, justamente a aquella perspectiva que se puede llamar "emprendedorista". Esta configuración responde a lo que se puede definir como tendencias y dinámicas de la tercera fase de la modernidad global. En lo que sigue empezaré discutiendo su funcionamiento concreto, luego retomaré algunos temas clásicos de la sociología y de la filosofía a fin de tematizarlo, concluyendo con su ubicación en la modernidad contemporánea y los sistemas de dominación global. 


\section{De los derechos a las políticas particularizantes}

La política social global no puede ser descrita de manera homogénea para todo el mundo. Hay variaciones históricas y contemporáneas que son muy significativas. En Occidente, encontramos desde fines del siglo XIX y durante el siglo XX, sobre todo en su segunda mitad, una tendencia a la universalización de los derechos sociales -incluso como proyecto de una socialdemocracia liberal, cuya referencia clásica es el conocido trabajo de Marshall ([1950] 1964)—, aunque por otra parte sistemas corporativos, como el alemán, también hayan cumplido un rol decisivo, y este tipo de construcción del bienestar social haya sufrido en buena medida una derrota en Estados Unidos - donde es residual-. Corporativismo fue también la manera en que América Latina y el mundo árabe desarrollaron sus políticas sociales, a diferencia de los países socialistas que buscaron políticas más universalistas, como fue el caso de la Unión Soviética, si bien China ha separado claramente sus poblaciones rurales y urbanas, estas sí, merecedoras de derechos sociales más amplios.

Así, el mercado fue el eje fundamental original del proyecto moderno, al lado de la ciudadanía civil y en parte política, y en los Estados del bienestar se fue extendiendo a la ciudadanía social, durante los siglos XIX y XX. Muchas veces, sin embargo, desde la segunda mitad del siglo XX el tema de la acción afirmativa apareció en varios lugares, como India, merced a un tejido social heterogéneo y atravesado por profundas desigualdades (en este caso, de casta). Los derechos de cariz universal, de todos modos, al menos de manera retórica y como telos, se mantuvieron como objetivo estatal y de muchos actores en la mayoría de los países. Desde la crisis de los años 1970 esta situación cambió. Ya no son los derechos o su proyección lo que importa. Es decir, no es la igualdad, sino la equidad (Domingues, 2002). En este sentido lo que importa no es tratar a todos de la misma manera en búsqueda de una justicia que constituya un "status común", en otras palabras, universal. Al revés, se trata de generar políticas que tratan a distintos actores, desiguales en su situación, de manera desigual. Nadie expresó de manera más directa y argumentada esta mirada que Amartya Sen (1999), cuya perspectiva se presentó además directamente en contra, aunque de manera implícita, del desarrollismo que nos habría defraudado - se supone- en el Tercer Mundo.

Según este punto de vista, la cuestión sería elegir a los más necesitados. Las políticas focalizadas serían por lo tanto la solución, las cuales recogieron los fundamentos de las políticas compensatorias, es decir, para la protección de los más "vulnerables" de cara a los "ajustes estructurales" impuestos por las políticas derivadas del Consenso de Washington y planteadas por las propias organizaciones financieras internacionales, una vez que era muy clara la magnitud de su impacto negativo inmediato, que debería revertirse en el largo plazo. No es una casualidad que Sen haya ganado un premio y un homenaje del Banco Mundial. Si su contribución decisiva para el establecimiento del Índice de Desarrollo Humano (IDH) y en 
el establecimiento de las Metas del Milenio, de la Organización de las Naciones Unidas (ONU), para combatir la pobreza extrema, no se puede soslayar su rol en el desarrollo de las políticas dirigidas a los pobres — miserables, sería más correcto decir-, de hecho combinándose en buena medida ambas perspectivas. El programa brasileño "Bolsa Família" se convirtió en el más importante del mundo en este sentido, abarcando a millones de familias y superando a otros, como "Oportunidades" en México. Sirve así como modelo, finalmente, para el propio Banco Mundial, como orgullosamente difunde el gobierno de Brasil. Este programa consiste en el ejemplo máximo de política social latinoamericana contemporánea, mientras India, con su enorme número de pobres, busca desarrollar un proyecto semejante, basado en transferencias monetarias directas, como en el Bolsa Familia, aunque tenga que luchar con problemas de estadística y administración (Jhabvala y Standing, 2010; Vyasulu, 2010; Gosh, 2011) ${ }^{1}$.

En el campo de la salud, además, el rechazo a la universalización de los servicios prestados por el Estado se convirtió en un tema crucial, una vez más con la defensa de que su oferta pública sería restringida a la atención básica y a los tratamientos generales. Así tendrían los pobres acceso a ellos. Los otros, de mayor "complejidad" y más caros, serían ofertados en el mercado a quiénes pudieran pagar. Una cobertura razonable se encuentra así en el horizonte, pero no la universalización ciudadana de los servicios de salud estatales. Con la educación pasó lo mismo, con la básica planteada como obligación del Estado - y formadora de "capital humano"-, mientras la enseñanza superior debería ser ofertada por el mercado, en el cual la comprarían las capas medias y altas. En todos los temas luce por lo tanto la cuestión de la equidad, no de la igualdad, como el propio Banco Mundial y el Fondo Monetario Internacional (FMI) dejaban claro.

Éste no fue el único tema en que hubo cambios significativos en las políticas sociales de estas instituciones. Otros temas emergieron bajo la presión de la opinión pública en los diversos países y la acción de Organizaciones No Gubernamentales (ONGs): se referían a demandas de grupos específicos o remitían a temas específicos. En primer lugar estaban los pueblos originarios, en particular en las Américas y en Australia, pero también en otros lugares de Asia y África, además del tema del medio ambiente, a menudo mezclándose con éste y creando oportunidades para que se desarrollaran nuevamente políticas sectorializadas en relación a colectividades específicas. El caso de las mujeres continuó, con las políticas sociales que tenían su promoción como objetivo, en un mundo dominado por los hombres y el machismo, buscando nuevamente tratar a los desiguales como desiguales y concentrando en

\footnotetext{
${ }^{1}$ Ver el panorama y argumentos trazados en Fiszbein y Schady et al. (2009). Este "informe de investigación" del Bando Mundial nos brinda datos y argumentos sociales liberales detallados a favor de las políticas focales de combate a la pobreza, así como sobre sus enlaces con el "capital humano", la salud y la educación. Sirve como telón de fondo en varios momentos de este artículo.
} 
ellas los beneficios y/o el control de la implementación concreta de las políticas públicas. En parte, aunque con menos intensidad, las cuestiones raciales y étnicas alrededor del mundo se volvieron también objeto de políticas sectorializadas de equidad. Además, cierto nivel de participación, bastante acotado sin embargo, se incluyó en la agenda de estos organismos.

Curiosamente, hay aún muy poca investigación sobre este proceso. Sobre pueblos originarios y medio ambiente, la evolución del Banco Mundial está ya más estudiada, pero en relación a los otros temas, no es ese para nada el caso. La mayoría de los estudios se dedica a sus proyectos de desarrollo desde los años 1940, en el estilo de apoyo a la infraestructura, industrialización de la agricultura, préstamos, etc. (Goldman, 2006; Pereira, 2011). La excepción es especialmente el trabajo de Hall (2007), que analiza varias de estas políticas, el paso de la economía, exclusivamente, a los temas ambientales y desde ahí a la política social, incluso las tensiones entre el banco y el gobierno de Estados Unidos en algún momento; sin embargo, no todas las políticas reciben su atención y en particular no llega a sacar las conclusiones posibles y necesarias, ni especificas ni mucho menos teóricas, acerca del significado y portada histórica de esta sutil evolución. Otras discusiones tratan de manera más genérica la cuestión, reconociendo que hay algo nuevo bajo el cielo. Este es el caso sobre todo de Hardt y Negri (2000), que proponen la tesis de un Imperio desterritorializado, en que los Estados ya no cumplen un rol decisivo, o al menos lo comparten con otros agentes, en la gestión del espacio global y en la biopolítica. La propia generación y el manejo de la vida y de la subjetividad serían los elementos fundamentales del capitalismo contemporáneo, de una manera que fragmenta la vida social, aunque la "multitud", mezcla de universalidad y singularidad, se ponga como el sujeto que al fin pondrá termino al imperio. Desde otro ángulo, local en vez de global, con referencia concreta a la India, Chatterjee (2004) criticó las políticas estatales de ciudadanía social y afirmó el rol de los temas e identidades morales particulares y circunscritas que los sujetos concretos serían capaces de generar, contraponiéndose a la "gubernamentalidad" ejercida por el Estado - una manera de "gobierno" (rule), no de "dominación", afirma él, lo que para mí es más bien retórico que propiamente conceptual, puesto que la última es un componente de la primera-.

Hay que reconocer también que éste no fue un movimiento desplegado simplemente desde arriba. En la dinámica social muchas colectividades hicieron escuchar demandas cada vez más particularizadas, de manera novedosa o encontrando oportunidades y espacios para hacerlas más visibles que en periodos anteriores. Las formas de participación democrática de estos grupos también se hicieron más fuertes y encontraron receptividad nacionalmente y frente a algunas organizaciones internacionales, con la ampliación de lo que algunos quisieron definir como una "sociedad civil global" (Kaldor, 2003). Se plantearon de este modo una multiplicidad de cuestiones. 
Por otra parte, el tema del "emprendedorismo" se mantuvo central para todas estas políticas. De hecho, se buscan colectividades como objetos, más o menos pasivas o activas, pero es muy común que la solución termine por ser la promoción de la actividad empresarial - al menos y sobre todo retóricamente- de los beneficiarios de las políticas, en particular cuando se trata del combate a la pobreza. En este sentido es clara la combinación entre el social liberalismo y el neoliberalismo, en que aquél no se separa de éste, ambos complementándose desde hace un buen rato, más allá de una pura y simple afirmación del mercado, pero nunca negándolo y principalmente manteniéndolo como el cierne del desarrollo social. El ejemplo más claro, pionero e inspirador de programas o aportes a programas, que se destaca en esto caso es, por supuesto, el del "Grameen Bank" en Bangladesh. Se presta dinero a los muy pobres, suponiendo que serían las mujeres las que recibirían el beneficio especialmente - lo que concretamente es mucho más complicado, aunque este sea un tema que se suele encontrar en todas las políticas sociales de combate a la pobreza hoy-: uno saldría de esta situación de privación volviéndose un emprendedor, un empresario de sí mismo, una manera novedosa y racionalizada de divulgación y promoción del "cuentapropismo" del Tercer Mundo, versión latinoamericana, africana o asiática (Karim, 2008; Gosh, 2013) .

\section{Individualismo, particularismo y universalismo, pluralismo y complejidad}

Se encuentra más que establecido el carácter individualista del pensamiento liberal, y esta concepción se reproduce en el neoliberalismo, aunque no se deben olvidar los temas institucionales y legales que permiten, según este tipo de concepción del mundo, plantear la posibilidad de la vida social e incluso la creación o preservación de la libertad. Lo mismo pasó con la manera en que se comprendió la racionalidad del comportamiento emprendedor, una vez que demanda un ambiente de alta previsibilidad. Estos son todos temas de la "gobernanza" global y las reformas legales y sociales planteadas por las organizaciones internacionales en las últimas décadas. Este tipo de perspectiva conlleva, por otra parte, un universalismo abstracto bastante pronunciado: el individuo racional —así como las formas institucionales básicas que garantizan un ambiente óptimo para su actuación- es universal y atraviesa todas las regiones y países - más allá de su predominancia histórica original en Occidente- En desmedro de las fronteras nacionales, se debería verlo como una figura que finalmente encontró en el mundo moderno, global, las posibilidades

\footnotetext{
${ }^{2}$ Lo que eso significa en términos de "pequeña producción mercantil" y autoexplotación, se puede observar, en referencia a África y el Sur de Asia - pero este fenómeno es también muy conocido en América Latina-, en Harriss-White (2012).
} 
concretas de su realización, como de hecho sugería Hayek ([1944] 1979), con su teleología del desarrollo histórico: hay algo como una esencia del ser humano, se puede decir, pero ésta se revela solamente en la modernidad, cuando se encuentran las formas adecuadas a su realización social. De ahí que el desarrollo económico, permitido por la libertad de acción del individuo, por primera vez haya podido hacerse de manera consistente, siendo Europa y Estados Unidos los primeros en lanzarse a este proceso, a pesar de las amenazas que el crecimiento del Estado durante el siglo XX generaba para la libertad humana, con la emergencia de una nueva forma de servidumbre, creía él. El individualismo del liberalismo es mantenido en su hermano más nuevo, como se advierte, por ejemplo, claramente en Sen, pero hay ahí un cambio de enorme importancia.

De cierto modo, se despliega un proceso semejante al que tuvo lugar en la Europa del siglo XIX (véase Castel, [1995] 1999), aunque algo más limitado: mientras en aquel momento el liberalismo tenía que enfrentarse con la permanencia del "pauperismo" - la pobreza seguía vigente y era una cuestión incómoda, atentando, dada su falta de éxito en resolverla, contra el establecimiento de los principios de la economía liberal capitalista-, hoy se reconoce que la pobreza aguda es un problema global, al que hace falta responder. No es que se piense que el liberalismo no la puede solucionar en el largo plazo. Se admite que los que son demasiado pobres necesitan condiciones mínimas para poder ascender a la condición de emprendedores. Para ello tienen que ser tratados de manera diferenciada en relación a los otros sectores de la sociedad. No es la igualdad lo que se plantea, por lo tanto, sino la equidad. Es con este tipo de percepción que se han dividido las sociedades de fines del siglo XX e inicios del XXI en colectividades específicas, con identidades particulares y cada vez más cerradas, dentro de los Estados nacionales, pero en un cierto sentido también desde un punto de vista internacional. De estas identidades se excluyen las clases sociales, por otra parte, que podrían tematizar sobre todo el capitalismo, o al menos plantear frenos a su funcionamiento y a las relaciones de explotación que le caracterizan. Se trata de un tema que el liberalismo estadounidense desde hace tiempo proyecta intelectual y políticamente, con las fundaciones privadas de aquel país cumpliendo un rol claro en su articulación y difusión, primero nacional y luego global (Herz, 1989; Domhoff, 2010).

Anderson (1998) hizo la apología del nacionalismo como una manera de afirmar el universalismo moderno, que promovería lo que llamó "serialidades abiertas". Las contrapuso a las identidades etnicizadas, que comparten, según él, el carácter de "serialidades cerradas". Chatterjee (2004) se acercó más al tema que planteo aquí, al referirse, todavía atacando el nacionalismo y señalando que los derechos sociales marshallianos ya evidenciaban una tensión en su construcción, una vez que era más difícil definirlos universalmente y de este modo concretamente universalizarlos —de hecho, nacionalizarlos, se puede decir-. Así demandó prioridad para las serialidades cerradas de las comunidades populares moralmente definidas, que se vuelven focos más o menos definidos de las políticas sociales estatales y en sus 
relaciones con ONGs (véase Domingues, 2009, 2012). Chatterjee traduce, por consiguiente, de modo positivo en un espíritu muy anti-estatal común en la intelectualidad indiana, procesos de alcance global, que se difunden por todos $-\mathrm{o}$ casi todos - los países del mundo contemporáneo. Es decir, si el liberalismo enfatizaba una mezcla de individualismo y derechos civiles, con su versión socialdemócrata haciendo lo mismo, pese a las dificultades de definición y prácticas, con los derechos sociales que extendían los derechos civiles - y en alguna forma los políticos, que nunca estuvieron en el centro del pensamiento liberal o eran rechazados de alguna manera-, lo que se dibuja hoy es algo muy distinto. Dentro de cada país y transversalmente en términos globales, lo que se presenta es una mezcla de individualismo y particularismos identitarios y sociales. Si antes, en consecuencia, eran derechos universalizados, al menos en su concretización legal en el seno de la nación, lo que se ponía como meta, lo que cuenta hoy es más bien la concretización de políticas específicas para cada grupo social —en su aislamiento en relación a los otros-. Es ésta la cara social del liberalismo contemporáneo, sobrepasando y combinándose con el neoliberalismo en su forma más pura.

Estos grupos pueden ser definidos de manera más o menos activa o pasiva. En verdad muchos de ellos emergieron por su propia cuenta, sin vínculos con proyectos de grupos dominantes. Ello se expresa de manera visible en los Consejos creados por la Constitución de 1988 en Brasil, en los que temas y colectividades diversas fueron seleccionados como ejes para la democracia participativa, que complementaba la democracia representativa convencional. Mujeres y homosexuales, grupos étnicos y raciales, juventud y tercera edad, entre otros, son colectividades que expresan el nivel creciente de complejidad y pluralismo social del mundo moderno contemporáneo, conjuntamente con otros grupos o movimientos sociales tratando temas específicos y ellos también ampliamente pluralizados. No son frutos de una actividad exclusivamente autocentrada, al revés, interactúan en su formación con el Estado, las políticas públicas, ONGs, iglesias, clases, sindicatos, otros movimientos y organismos internacionales. También la cuestión social, no como desigualdad, sino como pobreza o incluso miseria, es un tema que se puso en tela de juicio por luchas sociales más amplias que terminaron inevitablemente imponiéndole una agenda al Estado y a los gobiernos de turno, sin que, entretanto, hubiera una solución que privilegiara su tratamiento como objeto esencialmente pasivo y aislado de los otros sectores sociales. Ésta fue una construcción intelectual y política decisiva para nuestro mundo contemporáneo, en términos identitarios, de política social y de desarrollo. En algunos casos, es mucho más jerárquica y demanda pasividad, lo que es típico del tratamiento de la pobreza, que asume elementos de filantropía desplegada desde arriba por el Estado, incluso con cierta definición de cuáles son los pobres merecedores y de los que no lo son - "condicionalidades" mediante-; en otros, implica la participación activa de estas colectividades en la elaboración de políticas públicas, de modo más o menos participativo. 
No todos los países del mundo están bajo la influencia de este tipo de política, sino sólo aquellos que se alinean de algún modo a la tradición liberal, en América Latina o Asia (India sí, China no, por ejemplo, Japón recién se está planteando esta posibilidad), mientras África también se encuentra enmarcada en esta política. Europa, a mediano plazo, al menos en algunos de sus países del sur, puede acabar asumiéndolas, con Estados Unidos, en escala reducida, básicamente tratando a sus pobres sólo por medio de políticas específicas y muy restrictas ya desde hace bastante tiempo, sobre todo después de la ascensión del neoliberalismo, además de haber, al menos desde los años 1970, desarrollado una fuerte "política de la identidad" particularizante. De todos modos, se trata hoy de una referencia fundamental para las políticas globales y para la concepción que uno tiene de su identidad, de lo que significa ser sujeto - como miembro de un grupo principalmente cerrado, no de una colectividad más amplia, sea de ciudadanos, de clase, nacionalmente integrada-, fenómeno cuyos andamiajes sociales hace falta señalar aquí de manera al menos somera.

El trasfondo de estas nuevas maneras de pensar la vida social, las políticas sociales y la propia producción de la vida y de la subjetividad, se encuentra en procesos evolutivos de largo plazo, así como en la evolución más limitada de la civilización moderna (véase Domingues, 2002, 2012). Las dos primeras fases de desarrollo de la modernidad (la liberal/colonial y después la estatalmente organizada) tuvieron proyectos de homogeneización de la vida social entre sus objetivos centrales, sea buscando la dominación, sea planteando la emancipación. Éstas fueron también maneras de tratar e intentar reducir la complejidad social. Hoy en día tal proceso ya no es posible: el nivel de complejidad social, que implica un alto grado de pluralismo, en términos de subjetividad individual y colectiva, no se deja capturar por proyectos de homogeneización modernizadora sin más, por "giros modernizadores" desplegados por colectividades de cualquier tipo, que tengan como intención una homogeneización radical de la vida social. He ahí lo que hace plausible, aunque problemática, la concentración en serialidades cerradas. Sin embargo, hay que tener cuidado con la absolutización de la valoración práctica de este tipo de colectividad, una vez que la imposibilidad de una homogeneización de la vida social de manera más radical no quiere decir que no pueda ser alcanzada de manera parcial en algunos campos, con efectos incluso positivos sobre la vida social desde el punto de vista emancipatorio. Ha sido siempre una mezcla de serialidades abiertas y cerradas, construidas de maneras variables, que respondió por el tejido social y la dinámica de la modernidad. Este sigue siendo el caso, con menos espacio para la primera, pero seguramente sin que el balance entre universalismo y particularismo se pueda suponer volcado hacia la segunda de manera total. 


\section{3. ¿Políticas públicas más allá del social liberalismo?}

Hemos visto entonces que las políticas públicas de equidad se volvieron fundamentales contemporáneamente, y que son acompañadas y a veces se mezclan con políticas sectorializadas, dirigidas para colectividades específicas. Los "pobres" son justo el punto de cruce de estas políticas. De hecho, al abarcar una enorme cantidad de personas, como en el caso del "Bolsa Família" brasileño, del "Familias en Acción" colombiano o del "Oportunidades" mexicano, así como potencialmente en el de India, se parecen a algo que es casi universal ${ }^{3}$. Pero no lo son. Además tienen como foco a las familias, no son en realidad para nada universales, ni mucho menos se plantean como derechos sociales, sino como una especie de dádiva estatal, que tiene un elemento clientelar lejano pero real - aunque en la base estas cosas sean menos claras: los beneficiarios del programa son indicados por comités locales, en el caso brasileño, por ejemplo- (Domingues, 2009). Es ilustrativo que un rumor sobre el fin del "Bolsa Familia" por una decisión repentina de la presidenta Dilma Rousseff haya llevado a miles de personas, en el curso de un fin de semana, a buscar desesperadamente sacar su dinero de los bancos antes de que el gobierno supuestamente lo recogiera, terminando el programa. La "Asignación Universal por Hijo", programa argentino similar, que tampoco es universal, aunque también es dirigido a los pobres y su objeto siguen siendo las familias, es sin embargo más general y menos condicionado: no define colectividades directamente recortadas por el Estado, sino que depende de la demanda directa de las familias y es por lo tanto más ciudadano (Neri et al., 2010). Por otra parte, los gobiernos latinoamericanos fueron en muchos casos y momentos un poco más allá del social liberalismo, en el sentido estricto del término, por medio de la democratización y la creciente inclusión promocionada por sus políticas sectoriales, sin romper con ella y en desmedro de tensiones que surgieron con algunos grupos en función sobre todo de proyectos extractivistas de recursos naturales (en especial, la mega-minería) en toda la región.

Un argumento a favor de mantener este tipo de políticas focales es muy obvio y tiene plausibilidad económica y humana: permite alcanzar a los que más necesitan de estos aportes monetarios, sobre todo porque los programas no son demasiado caros, en una situación en que los Estados no tienen, se supone, recursos para abarcar a todos con políticas universales, que además serían injustas por derrochar recursos limitados con quienes, de hecho, no los necesitan. Otro argumento sería la alta complejidad social, que impide que el Estado trate todo lo que tiene que tratar

\footnotetext{
${ }^{3}$ A fines de 2010 los programas de transferencia monetaria directa en América Latina, los más grandes del mundo, alcanzaban a 113 millones de personas, es decir, el 19\% de la población de la región, cifra extraordinaria desde cualquier ángulo, aunque los valores transferidos sean en general muy pequeños y su demanda sobre el Producto Interior Bruto (PIB) sea igualmente muy modesta $(0,50 \%$ en el caso de Brasil, por ejemplo) (CEPAL, 2010).
} 
si no selecciona con cuidado sus objetivos y estrategias, lo que se pierde con políticas universales. Lo que remite en especial a la multiplicidad de políticas sectoriales, demandas por colectividades con identidades e intereses distintos y cada vez más particularizados, que en gran medida es una realidad difícil de ser enfrentada. Sin embargo, no hay por qué detenerse ahí. Si estos dos argumentos no son absurdos, hay por otro lado temas sociales, políticos y morales que necesitan ser encuadrados de otra manera. Si hay que aceptar el crecientemente heterogéneo carácter de la vida social y, por lo tanto, de las políticas públicas, no hay razón para que todas ellas sean pensadas con este diseño. Es posible, y necesario, pensar en políticas homogeneizadoras, de status social común, que tengan al ciudadano-trabajador como su sujeto de derechos, universales. Si se trataba de una ofensiva estatal particularizadora y heterogeneizante en el caso de aquellas políticas, en éste se trata de una ofensiva universalizadora y heterogeneizante. Su mezcla, concretando un sistema de solidaridad compleja (Domingues, [2006] 2007), es lo que se plantea para un programa avanzado de reformas sociales en América Latina y en el mundo de manera más general. Los recursos existen y hace falta simplemente que sean movilizados.

Con ello, nos movemos de hecho más allá del social liberalismo, hacia algo más cercano a la socialdemocracia y sus serialidades más abiertas, sobretodo en su versión ciudadana (no corporativista). En este sentido hay que cuidar también de pensar que no se trata de aplastar a las serialidades más particulares, aunque haya que rechazar cualquier esencialización de sus atributos, puesto que todas son construcciones sociales y, en tanto que tal, maleables y cambiantes. De todos modos, hubo una fuerte crítica desde los años 1970-1980 al desconocimiento de estos elementos particulares de las identidades sociales. De hecho, mucha de la teoría social crítica durante el siglo XX se dirigió a las operaciones "logocéntricas" que achatan la realidad social mediante conceptos y políticas que no permiten el florecimiento de la diversidad, constituyéndose en uno de los elementos fundamentales, aunque no exclusivo, de los sistemas de dominación durante aquel periodo (Domingues, 2002). Esta perspectiva debe ser sostenida, abriendo espacio para la lucha identitaria y de intereses variados que se pueda encontrar en toda y cualquier sociedad nacional, atravesándolas. Pero no hay por qué quedarse ahí, reificando las particularidades y razonando como si los elementos nacionales y globales homogeneizadores nunca hayan tenido o ya no tuvieran un rol importante a jugar. Al revés, en una situación en que las políticas de dominación y sus facetas de gubernamentalidad se basan en la fragmentación social, es en la construcción de una solidaridad compleja que mezcle heterogeneidad y homogeneidad donde hay aspectos que importa considerar y promocionar, sobre todo si estos elementos se presentan de forma activa antes que pasiva.

Hoy vemos en Europa a la izquierda poniéndose a la defensiva por cuenta del desmantelamiento en mayor o menor medida del Estado del bienestar, dependiendo del país y de la legislación laboral su flexibilización, de manera bastante general. Es 
como si de golpe la defensa de las conquistas de la socialdemocracia fuera todo lo que debería movilizar a esta fuerza política. Ello no es ni debería ser visto como cierto, pero es necesario reconocer que éstas fueron realizaciones de alcance civilizatorio decisivo. No se trata de detenerse en la construcción de un Estado del bienestar, sino de establecer globalmente una ciudadanía social compartida y potencialmente universal. Este es un elemento que hoy se contrapone a los proyectos de dominación y construcción de una ciudadanía que recorta la sociedad en colectividades y demandas inconmensurables y lleva a la fragmentación. Además no se trata de demandar la copia de modelos anteriores socialdemócratas europeos por todas partes, sino de buscar construir proyectos de cariz inevitablemente global, con cierta autonomía regional y nacional, tal y como ocurre en América Latina en las últimas décadas (Pereira da Silva, 2010). Necesitamos abrir así estas particularidades supuestamente inconmensurables y construir una solidaridad que reconozca lo que tenemos de específico, a la vez que nuestra pertenencia a la especie humana - y a nuestras modernas sociedades nacionales, mientras éstas nos den la forma fundamental de concretizar legalmente derechos- es también universalmente establecida mediante un concepto amplio y robusto de ciudadanía.

Por supuesto, los temas de la dominación internacional no se agotan ahí, en esta configuración específica y sutil del social liberalismo. Incluyen también el desarrollo y el subdesarrollo, la dependencia y el imperialismo, el control de los circuitos de producción intelectual e ideológica, científica y tecnología, entre muchos otros elementos que componen las desigualdades y asimetrías del sistema moderno global. Hay que combatirlas en todos sus aspectos y caras, en busca de una sociedad global más justa. La gestión de la vida social tal cual la retraté aquí juega de todos modos su rol fundamental en la articulación de políticas públicas y de la subjetividad, individual y colectiva. En su contra, hay que buscar los caminos que nos lleven a su crítica y superación emancipadoras.

\section{Conclusión}

A modo de conclusión podemos retomar y profundizar entonces la interrogante sobre cómo se posiciona la teoría crítica a lo largo de las metamorfosis de la modernidad. Originalmente, en su momento fundacional, con Marx ([1867] 1987), la teoría crítica buscó mostrar cómo, por detrás de las aparentemente justas relaciones de trabajo asalariadas bajo el dominio del capital - y en parte, verdaderamente, una vez que la fuerza de trabajo es vendida por su justo precio- se ocultaban relaciones profundas y regulares de explotación. Marx fue además muy claro sobre el carácter global del sistema capitalista, aunque tuviera una visión optimista de su penetración en todos los países del mundo, lo que brindaba a largo plazo condiciones para un comunismo planetario. Eso correspondió a la primera fase de la modernidad, en el siglo XIX e inicios del XX, en que el mercado como realidad y como telos se 
proyectaba como el pilar fundamental de la vida social, la expansión colonial e imperial conllevaba un Estado más fuerte capaz de cumplir esta misión civilizatoria, al fin de la cual todos los países y regiones tendrían el mercado como mecanismo homogeneizador. La segunda fase de la modernidad, desde los años 1930 pasando por los procesos de descolonización y hasta una nueva crisis del sistema en los años 1970, tuvo el Estado y un esfuerzo más general de homogeneización como su proyección global. Adorno y Horkheimer ([1944-45] 1984), entre otros, hicieron hincapié justo en la homogeneización del mundo — de hecho, en su caso, concretamente solamente Occidente y el mundo soviético- por medio de la razón. En su "logocentrismo", ella no reconocería nada que simplemente no la reprodujera en el mundo real -destruyendo lo que escapaba a sus operaciones, lo que el colonialismo, cabe notar, ya había llevado a cabo a amplia escala fuera de Europa, incluso en Estados Unidos-. De cierta manera es como si estos autores refractaran las actividades del Estado desde donde ahora más claramente se desplegaba una razón que pretendía organizar, de manera profunda y por mecanismos diversos, las sociedades nacionales ${ }^{4}$.

En el período que nos toca vivir, en que está vigente la tercera fase de la modernidad global, la complejidad de la vida social se volvió tan alta que ya no es posible pensar en sistemas de dominación fundamentalmente homogeneizantes e incluso en fuerzas emancipadoras con el mismo cariz, lo que se muestra aún más acentuado en razón de su carácter claramente global y en tanto tal irreductiblemente heterogéneo, con las herencias de las diversas regiones haciéndose más sobresalientes. Por eso el social liberalismo global se plantea con gran astucia al mismo tiempo como homogeneizador - mediante el emprendedorismo- y fragmentador - por medio políticas focales y sectorializadas-. La teoría crítica mientras reconoce y abraza la complejidad social, especialmente desde el punto de vista de las colectividades que aspiran a la emancipación, no puede dejarse capturar por una particularización excesiva de la vida social. Hay que saber combinar particularidad y universalidad para que podamos desplegar un proyecto capaz de dar cuenta de los retos que se nos plantearan a lo largo del siglo XXI.

\section{Bibliografía}

Adorno, Theodor W., y Horkheimer, Max ([1944-45] 1984) Dialektik der Aufklärung. Frankfurt am Main: Suhrkamp.

\footnotetext{
${ }^{4}$ Aunque Foucault (por ejemplo, [1978-79] 2004) nos haya en su momento demostrado que el Estado, en algunos aspectos cruciales de la vida social, ya se hubiera ocupado de esto a través de mecanismos de "gubernamentalidad" desde el siglo XIX.
} 
Anderson, Benedict (1998) The Spectre of Comparisons: Nationalism, Southeast Asia, and the World. Londres y Nueva York: Verso.

Anderson, Perry (1995) "Balanço do neoliberalism", en E. Sader y P. Gentile (comps.) Pós-Neoliberalismo. São Paulo: Paz e Terra, 9-23.

Castel, Robert ([1995] 1999) Les métamorphoses de la question social. Paris: Folio.

CEPAL (2010) "Comunicado de prensa" [Puesto en línea 27/12/2010. URL: $<$ http://www.eclac.org/cgi-

bin/getProd.asp?xml=/prensa/noticias/comunicados/8/42138/P42138.xml\&xsl=/ $\mathrm{prensa} / \mathrm{tpl} / \mathrm{p} 6 \mathrm{f} . \mathrm{xs} 1 \&$ base$=/ \mathrm{prensa} / \mathrm{tpl} /$ top-bottom.xsl $>$, consultado el 12 de Junio de 2013].

Chatterjee, Partha (2004) The Politics of the Governed: Reflections on Popular Politics in Most of the World. Nueva York: Columbia University Press.

Domingues, José Maurício (2002) Interpretando a modernidade. Imaginário e instituições. Rio de Janeiro: FGV Editora. [Edición en inglês, Cardiff: University of Wales Press, 2006].

Domingues, José Maurício ([2006] 2007) "Instituições formais, cidadania e autonomia no Brasil contemporâneo", en J. M. Domingues (comp.) Aproximações à América Latina. Desafios contemporâneos. Rio de Janeiro: Civilização Brasileira, 193-206.

Domingues, José Maurício (2009) "Democracia, libertad y dominación: una discusión teórica con referencia especial (via India) a América Latina, Brasil”, en L. Tapia (comp.) Democracia y teoría política en movimiento. La Paz: CIDESUNSAN, 75-107.

Domingues, José Maurício (2012) Global Modernity, Development, and Contemporary Civilization: towards a Renewal of Critical Theory. Nueva York y Londres: Routledge.

Domhoff, William G. (2010) Who Rules America? Challenges to Corporate and Class Dominance. Nueva York: McGrawHill ( $6^{\mathrm{a}}$ ed.).

Fiszbein, Ariel, y Schady, Norbert et al. (2009) Conditional Cash Transfers: Reducing Present and Future Poverty: a World Bank Research Report. Washington, DC: World Bank.

Foucault, Michel ([1978-79] 2004) Naissance de la biopolitique. Cours au Collège de France. Paris: Seuil y Gallimard.

Goldman, Michael (2006) Imperial Nature: the World Bank and the Struggles for Social Justice in the Age of Globalization. New Haven (Conn.): Yale University Press.

Gosh, Jayati (2011) "Cash transfers as the silver bullet for poverty reduction". Economic and Political Weekly, vol. 46, núm. 21, 67-71.

Gosh, Jayati (2013) "Microfinance and the challenge of financial inclusion for development". Cambridge Journal of Economics, vol. 37, núm. 6, 1203-1219.

Hall, Anthony (2007) "Social policies in the World Bank". Global Social Policy, vol. 7, 151-175. 
Hardt, Michael, y Negri, Antonio (2000) Empire. Cambridge (Mass,): Harvard University Press.

Harriss-White, Barbara (2012) "Capitalism and the common man: peasants and petty production in Africa and South Asia". Agrarian South: Journal of Political Economy, vol. 1, 109-160.

Harvey, David (2007) A Brief History of Neoliberalism. Oxford: Oxford University Press.

Hayek, Friedrich A. ([1944] 1979) The Road to Serfdom. Londres: Routledge \& Kegan Paul.

Herz, Monica (1989) Política cultural externa e atores transnacionais. O caso da Fundação Ford no Brasil. Dissertação de Mestrado, Rio de Janeiro: UPERJ.

Jhabvala, Renana, y Standing, Guy (2010) “Targeting the 'poor': clogged pipes and bureaucratic blinkers". Economic and Political Weekly, vol. 45, núm. 26-27, 239-246.

Kaldor, Mary (2003) Global Civil Society: an Answer to War. Cambridge: Polity Press.

Karim, Lamia (2008) "Desmystifying micro-credit: the Grameen Bank, NGOs, and neoliberalism in Bangladesh". Cultural Dynamics, vol. 20, 5-29.

Marshall, T. H. ([1950] 1964) "Citizenship and social class", en Class, Citizenship and Social Development. Garden City (New York): Double Day \& Co, 65-102.

Marx, Karl ([1867] 1987) Das Kapital: Kritik der politischen Ökonomie, vol. 1, en MEGA II-5. Berlín: Dietz.

Neri, Aldo et al. (2010) Asignación universal por hijo: ciclo de conferencias. Buenos Aires: AAPS.

Panitch, Leo, y Gindin, Sam (2012) The Making of Global Capitalism: the Political Economy of the American Empire. Londres y Nueva York: Verso.

Pereira, João Marcio Mendes (2011) O Banco Mundial como ator político, intelectual e financeiro. Rio de Janeiro: Civilização Brasileira.

Pereira da Silva, Fabricio (2010) Vitórias na crise. Trajetórias das esquerdas latino-americanas. Rio de Janeiro: Ponteio.

Sen, Amartya (1999) Development as Freedom. Nueva York: Knopf.

Vyasulu, Vinod (2010) 'Brazil's 'Fome Zero' strategy: can India implement cash transfers?". Economic and Political Weekly, vol. 45, núm. 26-27, 98-95. 